\title{
Study of the Relation between Parenting Style and Attitude with Physical Activity, Diet Behavior and Health of Children (10-13 Years): A Descriptive Cross - Sectional Study
}

\author{
Fatemeh Jahani ${ }^{1}$ \\ ${ }^{1}$ Department of Allied Hospitality Studies, Manipal Academy of Higher Education, Karnataka, India \\ Correspondence: Fatemeh Jahani, Department of Allied Hospitality Studies, Manipal Academy of Higher \\ Education, Karnataka, India.
}

Received: May 7, 2020

Accepted: July 7, 2020

Online Published: November 30, 2020

doi:10.5539/jmbr.v10n1p103

URL: https://doi.org/10.5539/jmbr.v10n1p103

\begin{abstract}
Background. Due to the significant and Irrefutable effects of parental style on children and the lack of a comprehensive studies on this topic, the present study aimed to study the relation between parenting style and attitude with physical activity, diet behavior and health of children (10-13 years).

Materials and Methods. This study is a descriptive cross - sectional study and conducted in schools located in Manipal and Udupi (Karnataka, India) during May 2017 to November 2017. A well designed questionnaire was administrated to children which included general information, along with physical activity questionnaire. The questionnaire also comprised of various other anthropometric measurements like BMI, MUAC, and Waist hip Circumferences etc. The data collected was subjected to statistical analysis using SPSS version 21. BMI has been calculated using anthroplus 1.0.4.

Results. The results of this study showed that there is a significant relationship between parenting style and diet behavior of the child $(\mathrm{P}<0.001)$. Parents with stylistic dimension in both authoritative and authoritarian have more influence on child for food avoidance and food approach. Studies shows an association between authoritarian and permissive parenting style with food approach behaviors and child weight status of children. parenting style is not affected on Childs physical activity. $74.8 \%$ of variation in weight is explained by the independent factors like parenting style, Nutrient intake, Food group intake, Physical activity level, Anthropometric measurement, and child eating behaviour questionnaire. There was a significant relationship between weight and these factors at $1 \%$ level $(\mathrm{F}=32.889, \mathrm{P}<0.001)$.

Conclusions. In conclusion, parents with stylistic dimension in both authoritarian and permissive style of parenting and parents with stylistic dimensions in all type of parenting style influences child physical activity. Parents with stylistic dimension in both authoritative and authoritarian have more influence on child for food avoidance and food approach behavior.
\end{abstract}

Keywords: Parenting style, Children, Physical activity, Diet behavior, Health

\section{Introduction}

Parents may unintentionally promote child weight gain by using wrong feeding methods such as stress, constraint, and control (Nobre, do Carmo Lessa, Lamounier, \& Franceschini, 2017). Closely one-third of all mothers classified their overweight child has a normal weight status than the measured weight status. Mothers were also more possible to categorize their daughters who were really at a danger of overweight as being overweight than their sons (Maynard, Galuska, Blanck, \& Serdula, 2003). Parents' observations of their own children's weight status are influenced by their children's features and do not seem greatly interrelated with their weight views of another child (Huang, Norman, Zabinski, Calfas, \& Patrick, 2007). Many of the study show that parents are unable to classify their child as overweight or obese. Parents felt that it was the doctor's duty as a health qualified to educate the matter with the child if he/she was worried about the child's weight as long as the talk involved guidance about the problem. While, mothers also stated that they would get disappointed if the doctor states that their child is overweight. If the child is overweight as same as their parents or any of their family members who were also overweight, mothers find it extra difficult to categorize their child as being overweight (Pagnini, Wilkenfeld, King, Booth, \& Booth, 2007). 
Parenting style is an emotional construct in which parent's behavior are expressed in child rearing. Mostly a child's food intake and physical activity is controlled by parents, parents can act as good models in selecting healthy food providing children with care also they can check the obtainability and approachability to different kind of foods available and the activity chances. Four types of parenting styles are Authoritative, Authoritarian, Permissive and Neglectful. Parents who encourage, support and consider the wishes of the child with appropriate boundaries are more likely to have children with healthy eating pattern and less overweight. Studies show that children of more authoritarian parents were more likely to become overweight(Russell, Taki, Laws, et al., 2016). Pathways showing influence of Parents on childs overweight and obesity provided in Fig. 1(Russell, Taki, Azadi, et al., 2016).

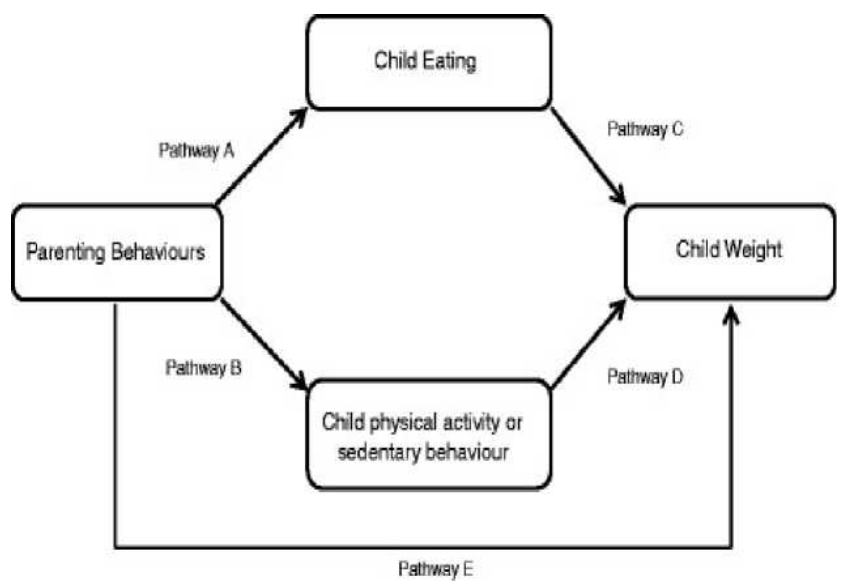

Figure 1. Pathways showing influence of Parents on Childs overweight and Obesity (Russell, Taki, Azadi, et al., 2016)

Findings on associations between parenting and child or infant weight and dietary intakes were generally suggestive of maternal feeding behaviors being in reaction to children's weight status. Parents with heavier children used more restriction and less pressure to eat. Parental feeding pressure and restriction were also associated with children's greater intakes of unhealthy foods and beverages in some, but not all(Russell, Taki, Laws, et al., 2016). Parental self-efficacy and parenting style are related with children's dietary comportment in early years of life. Parenting features matter for children's development of dietary behaviors. Parental self-efficacy and parenting style aimed interventions may be a promising approach to improve children's dietary behaviors. Interventions that address parental self-efficacy and parenting style have the potential to contribute to tackling childhood overweight and obesity(Xu, Wen, Hardy, \& Rissel, 2016).

Due to the significant and unintended effects of parental style on children and the lack of a comprehensive studies on this topic, the present study aimed to study the relation between parenting style and attitude with physical activity, diet behavior and health of children (10-13 years).

\section{Materials and Methods}

This study is a descriptive cross - sectional study and conducted in schools located in Manipal and Udupi (Karnataka, India) during May 2017 to November 2017. This cross sectional study is conducted to study the relation between parenting style and attitude with physical activity, diet behavior and health of children. age group 10-13 years. According to the result from previous study, sample size of this study was estimated to be 400 . The sampling technique used in this study was purposive sampling. Inclusion criteria in this study including all School going children of age 10-13 years both boys and girls and their parents and exclusion criteria including children with known case of thyroid hormone abnormalities and Children with co - morbid condition which can lead to overweight or underweight.

All parents are given subject information sheet to inform them about the study, subject of the study, study duration, location, benefits etc. A well designed questionnaire was administrated to children which included general information, along with physical activity questionnaire, 24 hour recall and food frequency of miscellaneous. The questionnaire also comprised of various other anthropometric measurements like BMI, MUAC, and Waist hip Circumferences etc.

Anthropometric measurement: Height was measured using measuring, weight is measured using weighing scale, BMI is expressed by formula, MUAC by MUAC tape, waist circumference is measured with help of measuring tape and waist to hip ratio is found. The body fat percentage was calculated using the formula The 
BMI classification.

Child eating behavior pattern questionnaire: The eating behavior questionnaire is a multidimensional questionnaire measuring child eating behaviors i.e., Enjoyment of food, Desire to drink, Satiety Responsiveness, Slowness in eating, Emotional under eating and food fussiness. The total sore of each category was added and computed with different variable (Carnell \& Wardle, 2007).

Parenting style questionnaire: was given to the parents to the parents to determine the parenting style adopted by each parents. Main categories of parenting styles are authoritarian, authoritative and permissive each category of parenting style was computed using total scores in each category. Parenting style is divided into 8 sub classes from the total scores obtained in each category like parents with low response to all parenting style, parents who are overall more permissive, parents who are overall more authoritarian, parents with stylistic dimension in both authoritarian and permissive, parents who are overall authoritative, parents with stylistic dimension in both authoritative and permissive, parents with stylistic dimension in both authoritative and authoritarian, and parents with stylistic dimension in all parenting style(Johnson, 2010).

The data collected was subjected to statistical analysis using SPSS version 21. BMI has been calculated using anthroplus 1.0.4.

\section{Results}

In this studySocio demographic classification is done considering gender, religion, education, occupation and income of the family. This has been tabulated in Table 1 .

Table 1. Socio Demographic profile of the Subjects of the study

\begin{tabular}{|c|c|c|}
\hline \multirow{2}{*}{ Socio Demographic Characteristics } & \multicolumn{2}{|l|}{$n=400$} \\
\hline & Frequency & Percent \\
\hline \multicolumn{3}{|l|}{ Gender } \\
\hline Male & 222 & 55.5 \\
\hline Female & 178 & 44.5 \\
\hline \multicolumn{3}{|l|}{ Religion } \\
\hline Hindu & 360 & 90 \\
\hline Muslim & 33 & 8.3 \\
\hline Christian & 6 & 1.5 \\
\hline Buddhist & 1 & 0.3 \\
\hline \multicolumn{3}{|l|}{ Fathers Education } \\
\hline Middle School Certificate & 104 & 26 \\
\hline High School Certificate & 89 & 22.3 \\
\hline Intermediate Or Post High School Diploma & 34 & 8.5 \\
\hline Graduate Or Postgraduate & 160 & 40 \\
\hline Profession Or Honours & 104 & 26 \\
\hline \multicolumn{3}{|l|}{ Occupation } \\
\hline Unskilled Worker & 21 & 5.3 \\
\hline Semi-Skilled Worker & 117 & 29.3 \\
\hline Skilled Worker & 50 & 12.5 \\
\hline Clerical, Shop Owner, Farmer & 118 & 29.5 \\
\hline Semi Profession & 39 & 9.8 \\
\hline Profession & 46 & 11.5 \\
\hline \multicolumn{3}{|l|}{ Family Income } \\
\hline $13874-1879$ & 57 & 14.2 \\
\hline $1898-36996$ & 91 & 22.8 \\
\hline $5547-9248$ & 25 & 6.3 \\
\hline $9249-13893$ & 51 & 12.8 \\
\hline $18498-36996$ & 38 & 9.5 \\
\hline$<=1865$ & 6 & 1.5 \\
\hline$>=36997$ & 132 & 33 \\
\hline \multicolumn{3}{|l|}{ Socio Economic Status } \\
\hline Lower Middle & 133 & 33.3 \\
\hline Upper Middle & 257 & 64.3 \\
\hline Lower & 10 & 2.5 \\
\hline \multicolumn{3}{|l|}{ Type of family } \\
\hline Nuclear & 290 & 72.5 \\
\hline Joint & 94 & 23.5 \\
\hline Extended & 16 & 4 \\
\hline
\end{tabular}


Table 2 indicates the different type of parenting style adopted by parents. From the table it is observed that 31.64 is the mean value of warmth and involvement which is higher than the other parenting categories. The mean value of democratic participation is 4.7 whereas good natured is 2.8 . For punitive strategy the mean value is found to be 8.6. Corporal punishment mean value is 4.47. 4.66 is the mean value for defectiveness. The mean value for verbal hostility is 4.59 while the mean value for follow through is 4.52 .5 .97 is the mean value for self-confidence. Most of the parents adopt authoritarian type of parenting style as the mean value is 39.15 . The mean value of authoritative type of parenting style is 22.33 , and the mean score of permissive type of parenting style is 10.49 .

Table 2. Mean scores of each categories of parenting styles

\begin{tabular}{ll}
\hline Parenting Style & Mean \pm SD \\
\hline Authoritative Parenting Style & $39.15 \pm 6.5$ \\
Warmth and involvement & $31.64 \pm 6.27$ \\
Democratic Participation & $4.7 \pm 1.30$ \\
Good Natured & $2.8 \pm 1.09$ \\
Authoritarian Parenting Style & $22.33 \pm 7.74$ \\
Non Reasoning, Punitive strategy & $8.6 \pm 3.47$ \\
Corporal Punishment & $4.47 \pm 2.28$ \\
Directiveness & $4.66 \pm 2.34$ \\
Permissive Parenting Style & 10.494 .4 \\
Verbal Hostility & $4.59 \pm 2.20$ \\
Follow Through & $4.52 \pm 2.18$ \\
Self Confidence & $5.97 \pm 3.34$ \\
\hline
\end{tabular}

Table 3 indicates the different categories of parenting style group adopted by the parents. From the table it is observed that $60(15 \%)$ of the parents adopt stylistic dimension in all parenting style.61 (15.25\%) of the parents choose stylistic dimension in both authoritarian and permissive style of parenting. 45(11.25\%) of parents have low response to all parenting style. Parents who are overall more permissive is $42(10.5 \%)$. $51(12.75 \%)$ of parents have authoritarian type of parenting style. Parents who are overall authoritative are 59(14.75\%). Parents with stylistic dimension in both authoritative and permissive style of parenting is $43(16.75 \%)$. 39(9.75\%) have stylistic dimension in both authoritative and authoritarian type of parenting style.

Table 3. Parenting style groups adopted by the parents

\begin{tabular}{lll}
\hline Parenting style group & Frequency & Percentage \\
\hline Parents with low response to all parenting style & 45 & 11.25 \\
Parents who are overall more permissive & 42 & 10.5 \\
Parents who are overall more authoritarian & 51 & 12.75 \\
Parents with stylistic dimension in both authoritarian and permissive & 61 & 15.25 \\
Parents who are overall authoritative & 59 & 14.75 \\
Parents with stylistic dimension in both authoritative and permissive & 43 & 16.75 \\
Parents with stylistic dimension in both authoritative and authoritarian & 39 & 9.75 \\
Parents with stylistic dimension in all parenting style & 60 & 15 \\
\hline
\end{tabular}

The results of this stud show that $74.8 \%$ of variation in weight is explained by the independent factors like parenting style, Nutrient intake, Food group intake, Physical activity level, Anthropometric measurement, and child eating behaviour questionnaire. There was a significant relationship between weight and these factors at $1 \%$ level $(\mathrm{F}=32.889, \mathrm{P}<0.001)$. Multiple linear equation was performed to determine the anthropometric measurement on Childs weight status. The results show that as the waist circumference increase by one centimetre the weight is increased by 0.053 centimetre. Similarly, if the hip circumference increase by one centimetre the weight increases by .519 centimetre. The regression coefficient for body mass index is 1.661 which indicates that as the body mass index increases by one $\mathrm{kg} / \mathrm{m}$ the weight is increased by 1.661 . As the waist hip ratio increases by one centimetre the weight increases by 0.032 . When the body fat percentage increase by one unit the weight increases by 0.034 kilograms. As the physical activity level increases by one unit the weight 
increases by 2.456 units. It is observed that as the cereal intake increases by one gram the weight increases by .015 kilograms. Similarly, as the pulses intake increase by one gram the weight increases by 0.005 kilograms. The coefficient of green leafy vegetable is .008 as the green leafy vegetable increases by one gram the weight decreases by .008 kilograms. If the intake of roots and tubers increases by one gram the weight is decreased by .013 kilograms. As the intake of other vegetable increases by one gram the weight decreased by .014 kilograms. The regression coefficient of fruits is .002 which means as the fruit intake increases by one unit the weight is decreased by 0.002 kilograms. As the milk and milk product intake increases by one gram the weight decreased by .003 kilograms. Similarly, as the nuts and seeds intake increase by one gram the weight increases by .014 kilograms. The coefficient of fats is 0.117 as the intake of fats increases by one gram the weight increases by 0.117 kilograms. As the sugar intake increases by one gram the weight increases by .108 kilograms. As the meat fish poultry increases by one gram the weight decreases by .003 kilograms. As the protein intake increases by one gram the weight is decreased by 0.003 kilograms. As the intake of total dietary fibre increases by one gram the weight decreases by 0.021 kilogram. Similarly, as the carbohydrate intake increase by one gram the weight increases by .002 kilograms. As the total saturated fatty acid intake increases by one microgram the weight increases by 2.55 kilograms. If the calcium increase by one microgram the weight increases by .002 . There is no relation between MUFA, and PUFA with the weight status of the children. From the results of this study it is observed that as the food Responsiveness increases the weight increases by .117 kilograms. Similarly, if the emotional overeating increases the weight decreases by -0.072 kilograms. If the enjoyment of food increases the weight increases by .323 kilograms. The coefficient of desire to drink is .206 which means as the desire to drink increases the weight increases by .206 kilograms. As the slowness in eating increases the weight increases by .004 kilograms if the satiety response increases the weight decreases by 0.014 . As the food slowness in eating increases the weight increases by .004 kilograms. Similarly, if the emotional under eating increases the weight decreases by .044 kilograms. If the food fussiness increases the weight increases by 0.061 kilograms.

The results of this study show a significant relation between authoritarian parenting style and educational success. Chi Square is used to find the relation between parenting style and academic performance of the child from the table it is observed that parents with who are overall authoritative and parents with stylistic dimension in all type of parenting style got the maximum score. Parents with stylistic dimension in both authoritative and authoritarian type of parenting style got the least score. Since the p value is 0.49 and chi-square value is 34.48 there is no significance between parenting style in child's academic performance.

Studies show that parents with more permissive style of parenting have child with more physical activity. Chi square is used to find the relation between parenting style and Childs physical activity of the child from the table 4.7.2 it is observed that parents with stylistic dimension in both authoritarian and permissive style of parenting and parents with stylistic dimensions in all type of parenting style have more percentage of score that is $15 \%$. Since the $\mathrm{p}$ value is 0.68 and chi-square Value is 17.7 there is no significance between parenting style in child's physical activity (Table 4).

Table 4. Association of parenting style and child physical activity level

Low Very

Parenting style group

Sedentary Active Active Active Total Chi.Sq Sig

Parents with low response to all parenting style

\begin{tabular}{|c|c|c|}
\hline $0 \%$ & $9.7 \% \quad 7.5 \% \quad 15 \%$ & $45^{\circ}$ \\
\hline $0 \%$ & $11.6 \% 7.5 \% \quad 8 \%$ & 43 \\
\hline & $13.4 \%$ & \\
\hline
\end{tabular}

Parents who are overall more permissive

nd

Parents with stylistic dimension in both authoritarian and permissive

$40 \%$
$0 \%$

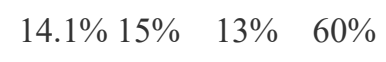

Parents who are overall authoritative $\quad 0 \%$

$15.5 \% 20 \% \quad 8 \% \quad 59 \% \quad 17.7 \quad 0.68^{\text {ns }}$

Parents with stylistic dimension in both authoritative and permissive
Parents with stylistic dimension in both authoritative and Parents with stylistic dimension in both authoritative and
authoritarian

Parents with stylistic dimension in all parenting style

$20 \% \quad 10.1 \% \quad 10 \% \quad 10 \% \quad 43 \%$

The results of this study show that the different group of parenting style is statistically significant with the food responsiveness as the $\mathrm{p}$ value is less than $0.001(\mathrm{p}<0.001)$. The different alphabets indicate significant difference 
in between the parenting style groups. In this study observed that parents with stylistic dimension in both authoritarian and permissive style of parenting have more mean score. There is a significant association between authoritarian and permissive style of parenting with food responsiveness $(p<0.001)$.

The mean score of authoritarian and permissive style of parenting is 2.45 . From the table it is observed that the different group of parenting style group is statistically significant with the emotional overeating as the $\mathrm{p}$ value is less than $0.001(\mathrm{p}<0.001)$. The different alphabets indicate significant difference in between the parenting style groups. Parents with stylistic dimension in authoritarian and permissive type of parenting style have more influence on emotional over eating (Table 5).

Table 5. Comparison of parenting style on emotional overeating

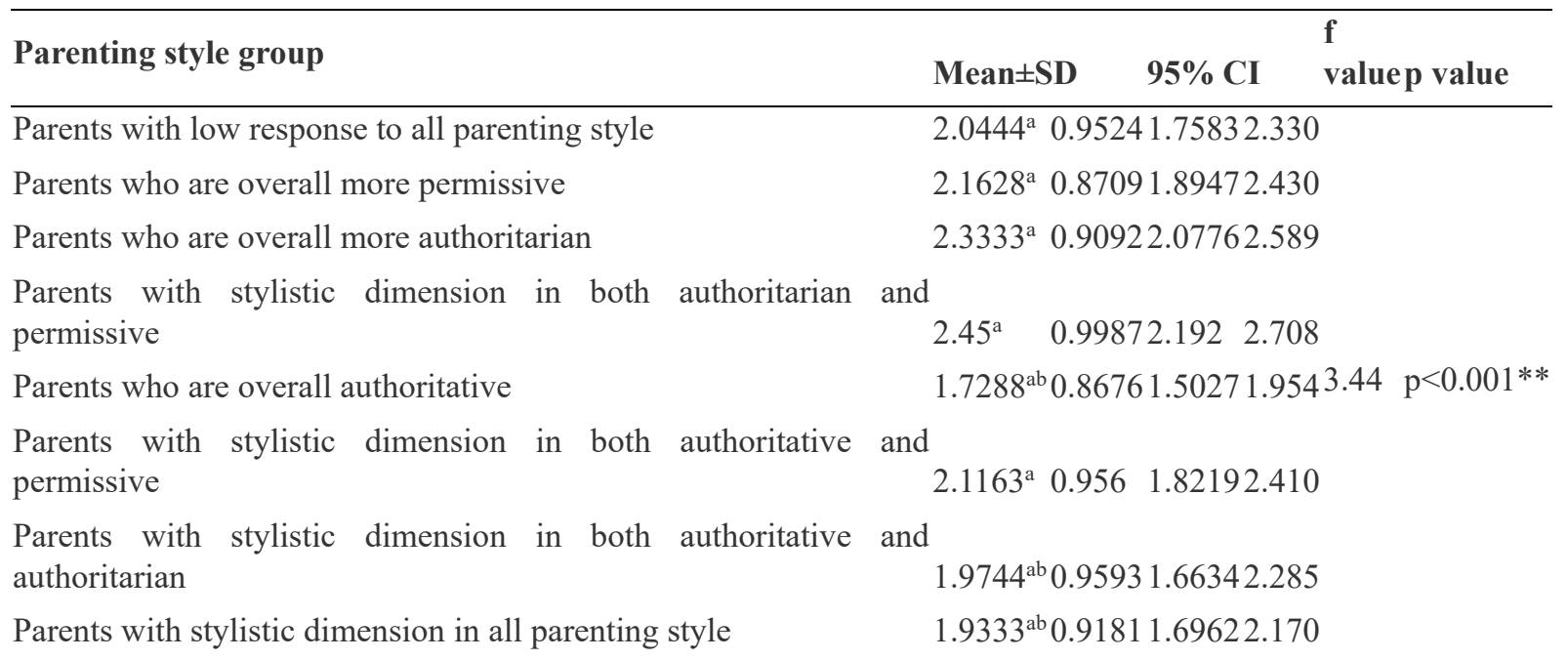

According to the results of this study the different parenting style group is statistically significant with the enjoyment of the food as the $\mathrm{p}$ value is less than $0.001(\mathrm{p}<0.001)$. The different alphabets indicate significant difference in between the parenting style group. Parents with stylistic dimension in both authoritative and authoritarian have the highest mean score. Which means there is an association between authoritative and authoritarian type of parenting style with food enjoyment.

From the Table 6 it is observed that the different group of parenting style group is statistically not significant with desire to drink $(p<0.001)$. The mean score or parents who are permissive is 7.23 which is the highest score which indicates a relation between permissive type of parenting and desire to drink. The different alphabets indicate significant difference in between the parenting style group (Table 6).

Table 6. Comparison of mean parenting style on desire to drink

\begin{tabular}{|c|c|c|c|}
\hline Parenting style group & Mean \pm SD & $95 \% \mathrm{CI}$ & $\begin{array}{l}\mathbf{f} \quad \mathrm{p} \\
\text { value value }\end{array}$ \\
\hline Parents with low response to all parenting style & \multicolumn{3}{|c|}{$6.288^{\mathrm{a}} 2.14925 .64326 .9346$} \\
\hline Parents who are overall more permissive & \multicolumn{3}{|c|}{$7.232^{\mathrm{b}} 2.21296 .55157 .9136$} \\
\hline Parents who are overall more authoritarian & \multicolumn{3}{|c|}{$6.745^{\mathrm{a}} 1.92716 .20317 .2871$} \\
\hline $\begin{array}{l}\text { Parents with stylistic dimension in both at } \\
\text { permissive }\end{array}$ & \multirow{2}{*}{\multicolumn{3}{|c|}{$\begin{array}{l}6.65^{\mathrm{a}} 1.85786 .17017 .1299 \\
6.152^{\mathrm{a}} 2.04955 .61846 .6866\end{array}$}} \\
\hline Parents who are overall authoritative & & & \\
\hline \multicolumn{4}{|c|}{ Parents with stylistic dimension in both authoritative and permissive $6.651^{\mathrm{a}} 2.23485 .96347 .3389$} \\
\hline \multicolumn{4}{|c|}{$\begin{array}{l}\text { Parents with stylistic dimension in both authoritative and } \\
\text { authoritarian }\end{array}$} \\
\hline Parents with stylistic dimension in all parenting style & $6.366^{\mathrm{a}} 2.154$ & 75.816. & \\
\hline
\end{tabular}

** indicates significance at 1\% level Different alphabet indicates significance between different groups

According to the results, the different group of parenting style group is statistically not significant with the satiety responsiveness $(\mathrm{p}$ value $=0.003)$. The different alphabets indicate significant difference in between the 
parenting style groups. Parents with stylistic dimension in both authoritarian and authoritative parenting style have more influence in satiety responsiveness. The results of this study show that the different group of parenting style group is statistically significant with the slowness in eating $(\mathrm{p}<0.001)$. The different alphabets indicate significant difference in between the parenting style groups. Parents with stylistic dimension in both authoritative and authoritarian have more significance with slowness in eating. In this study it is observed that the different group of parenting style group is statistically not significant with emotional under eating $(p=0.003)$. The different alphabets indicate significant difference in between the parenting style groups. Parents who are overall authoritarian and parents with more stylistic dimension in both authoritarian and permissive have more relation emotional under eating. About the comparison of mean parenting style on food fussiness, the results showed that the different group of parenting style group is statistically not significant with emotional under eating ( $p$ value $=$ 2.52). The different alphabets indicate significant difference in between the parenting style groups. Parents who are more authoritarian have influence on food fussiness.

Table 7 indicates parenting style with food approach. From the table it is observed that the different group of parenting style group is statistically significant with food approach $(\mathrm{p}<0.001)$. Parents with stylistic dimension in both authoritative and authoritarian parenting style have more influence on food approach since their mean value is more compared to the other parenting style group. The different alphabets indicate significant difference in between the parenting style groups.

Table 7. Comparison of mean parenting style on food Avoidance

\begin{tabular}{|c|c|c|}
\hline \multirow{2}{*}{ Food Avoidance } & \multicolumn{2}{|r|}{$f$} \\
\hline & Mean \pm SD & value $\mathrm{p}$ value \\
\hline Parents with low response to all parenting style & \multicolumn{2}{|c|}{$10.8667^{\mathrm{a}} 1.8290610 .317211 .4162$} \\
\hline Parents who are overall more permissive & \multicolumn{2}{|c|}{$11.6512^{\mathrm{b}} 1.7577511 .110212 .1921$} \\
\hline Parents who are overall more authoritarian & \multicolumn{2}{|c|}{$12.2157^{\mathrm{ab}} 1.2855211 .854112 .5772$} \\
\hline \multicolumn{3}{|c|}{$\begin{array}{l}\text { Parents with stylistic dimension in both authoritarian and } \\
\text { permissive }\end{array}$} \\
\hline Parents who are overall authoritative & \multicolumn{2}{|c|}{$11.2373^{b} 1.6010710 .82 \quad 11.6545^{4.721} \mathrm{p}<0.001^{* *}$} \\
\hline \multicolumn{3}{|c|}{$\begin{array}{l}\text { Parents with stylistic dimension in both authoritative and } \\
\text { permissive }\end{array}$} \\
\hline \multicolumn{3}{|c|}{$\begin{array}{l}\text { Parents with stylistic dimension in both authoritative and } \\
\text { authoritarian } \\
12.2051^{\mathrm{ab}} 1.6412411 .673112 .7372\end{array}$} \\
\hline Parents with stylistic dimension in all parenting style & $11.4167^{\mathrm{b}} 1.7591610 .9622$ & 11.8711 \\
\hline
\end{tabular}

The results of hypothesis testing presented in Table 8 .

Table 8. Hypothesis testing

\begin{tabular}{|c|c|c|c|}
\hline HYPOTHESIS (Ho) & TEST & $\begin{array}{l}\text { P- } \\
\text { VALUE }\end{array}$ & INFERENE \\
\hline $\begin{array}{l}\text { There is no significant relationship between parenting style } \\
\text { Behaviour, food group, Physical Activity Level, Anthropor } \\
\text { Measurement, Income of family and child eating behaviour }\end{array}$ & $\begin{array}{l}\text { tMultiple } \\
\text { cLinear } \\
\text { Regression }\end{array}$ & $\mathrm{P}<0.001$ & $\begin{array}{l}\text { H0 not accepted. } \\
\text { Alternate hypothesis } \\
\text { is accepted }\end{array}$ \\
\hline
\end{tabular}

\section{Discussion}

The present study aimed to study the relation between parenting style and attitude on physical activity, diet behavior and health of children. The results of this study showed that there is a significant relationship between parenting style and diet behavior of the child. Parents with stylistic dimension in both authoritative and authoritarian have more influence on child for food avoidance and food approach. Studies shows an association between authoritarian and permissive parenting style with food approach behaviors and child weight status of children. parenting style is not affected on Childs physical activity. $74.8 \%$ of variation in weight is explained by the independent factors like parenting style, Nutrient intake, Food group intake, Physical activity level, Anthropometric measurement, and child eating behaviour questionnaire. There was a significant relationship 
between weight and these factors at $1 \%$ level.

Parenting consist of a countless responsibility in shaping the behaviors' in children. Behavior's comprises of activity habits, diet, sleep and television viewing time. Parents can be a good role model to their child. Most children are likely to mimic or repeat the activities of their parents(Francis, Lee, \& Birch, 2003), so the parents have a direct impact on child's diet and physical activity. Parental influence may have an effect on over eating in children. While parents are the caretakers to the meals provided to the child, there can be variations in the child's fondness for meals(Costanzo \& Woody, 1985). On the other hand, parents who have more control on the diet behavior of their girl child had lower weight and BMI. Parenting style and restriction has been related with child's BMI(Joyce \& Zimmer-Gembeck, 2009). This topic need to be studied more to attain more specific result about relation between parenting style on physical activity and diet behaviour of the child. A longitudinal research linked parent's Body Mass index with their child's Body Mass Index, snacking habits, and television viewing both parent and child who are overweight had a raised BMI, along with rise in snacking and TV viewing time (Francis et al., 2003; Whitaker, Pepe, Wright, Seidel, \& Dietz, 1998).

Further features such as parent's literacy level, Salary, and the neighbourhood safety are in reversely linked to child Body Mass Index, with watching television has been known as the primary mediator(Cecil-Karb \& Grogan-Kaylor, 2009; Morgenstern, Sargent, \& Hanewinkel, 2009). Parenting styles has a significant part in the lifestyle factors and Body Mass Index of children. Four original parenting styles including: Authoritative (Provide clear approach and warm discipline), Authoritarian (Have clear power over the child and expects unquestioning obedience), Permissive (Allow child to make their own decisions and provide minimal punishment), and Permissive (Allow child to make their own decisions and provide minimal punishment)(Baumrind, 1966). The fourth typology, straightforward, characterized parents who had qualities of tolerance and provided the child slight warmth. These types of parents did not expect much from the child and had slight control over the child's behaviour (Maccoby, 1983). Parents who showed authoritative parenting style lead to better food choices and more activity levels in children(Golan \& Crow, 2004), while children of permissive parents had poorer intake of food and less control to unhealthy diet behavior. Research done to study parenting styles of low-income group sections have found that these parents have more authoritarian type of parenting style, irrespective of their culture(Pinderhughes, Dodge, Bates, Pettit, \& Zelli, 2000). This supports the power of effect of income that has on parent pressure, control, and feelings.

\section{Conclusions}

From the study it is observed that the parenting style is not affected on Childs physical activity but parents with stylistic dimension in both authoritarian and permissive style of parenting, parents with stylistic dimensions in all type of parenting style influences, parent who are overall more permissive, parents who are overall authoritarian and parents with stylistic dimension in both authoritative and permissive shows more relation with Childs physical activity. There is an influence of parenting style on child diet behaviour but there is a significance association between all the parenting style on food approach and food avoidance. Influence is seen in parents who adopt stylistic approach in both authoritative and authoritarian type of parenting with food approach and food avoidance.

\section{References}

Baumrind, D. (1966). Prototypical descriptions of 3 parenting styles. Psychology, 37, 1966.

Carnell, S., \& Wardle, J. (2007). Measuring behavioural susceptibility to obesity: validation of the child eating behaviour questionnaire. Appetite, 48(1), 104-113.

Cecil-Karb, R., \& Grogan-Kaylor, A. (2009). Childhood body mass index in community context: neighborhood safety, television viewing, and growth trajectories of BMI. Health \& social work, 34(3), 169-177.

Costanzo, P. R., \& Woody, E. Z. (1985). Domain-specific parenting styles and their impact on the child's development of particular deviance: the example of obesity proneness. Journal of social and clinical psychology, 3(4), 425-445.

Francis, L. A., Lee, Y., \& Birch, L. L. (2003). Parental weight status and girls' television viewing, snacking, and body mass indexes. Obesity research, 11(1), 143-151.

Golan, M., \& Crow, S. (2004). Parents are key players in the prevention and treatment of weight-related problems. Nutrition reviews, 62(1), 39-50.

Huang, J. S., Norman, G. J., Zabinski, M. F., Calfas, K., \& Patrick, K. (2007). Body image and self-esteem among adolescents undergoing an intervention targeting dietary and physical activity behaviors. Journal of Adolescent Health, 40(3), 245-251. 
Johnson, R. R. (2010). Parenting styles, child BMI, and ratings of obesigenic environments in families of children age 5-11.

Joyce, J. L., \& Zimmer-Gembeck, M. J. (2009). Parent feeding restriction and child weight. The mediating role of child disinhibited eating and the moderating role of the parenting context. Appetite, 52(3), 726-734.

Maccoby, E. E., Martin, J. A. . (1983). Socialization in the context of the family: Parent-child interaction. In P. H. Mussen (Ed.), Handbook of child psychology (Vol. 4, pp. 1-101). New York: Wiley.

Maynard, L. M., Galuska, D. A., Blanck, H. M., \& Serdula, M. K. (2003). Maternal perceptions of weight status of children. Pediatrics, 111 (Supplement 1), 1226-1231.

Morgenstern, M., Sargent, J. D., \& Hanewinkel, R. (2009). Relation between socioeconomic status and body mass index: evidence of an indirect path via television use. Archives of pediatrics \& adolescent medicine, 163(8), 731-738.

Nobre, L. N., do Carmo Lessa, A., Lamounier, J. A., \& Franceschini, S. d. C. C. (2017). Relationship between Overweight and Dietary Patterns in Brazilian Preschoolers. Food and Nutrition Sciences, 8(06), 598.

Pagnini, D. L., Wilkenfeld, R. L., King, L. A., Booth, M. L., \& Booth, S. L. (2007). Mothers of pre - school children talk about childhood overweight and obesity: The weight of opinion study. Journal of paediatrics and child health, 43(12), 806-810.

Pinderhughes, E. E., Dodge, K. A., Bates, J. E., Pettit, G. S., \& Zelli, A. (2000). Discipline responses: Influences of parents' socioeconomic status, ethnicity, beliefs about parenting, stress, and cognitive-emotional processes. Journal of family psychology, 14(3), 380.

Russell, C. G., Taki, S., Azadi, L., Campbell, K. J., Laws, R., Elliott, R., \& Denney-Wilson, E. (2016). A qualitative study of the infant feeding beliefs and behaviours of mothers with low educational attainment. BMC pediatrics, 16(1), 69 .

Russell, C. G., Taki, S., Laws, R., Azadi, L., Campbell, K. J., Elliott, R., . . Denney-Wilson, E. (2016). Effects of parent and child behaviours on overweight and obesity in infants and young children from disadvantaged backgrounds: systematic review with narrative synthesis. BMC public health, 16(1), 151.

Whitaker, R. C., Pepe, M. S., Wright, J. A., Seidel, K. D., \& Dietz, W. H. (1998). Early adiposity rebound and the risk of adult obesity. Pediatrics, 101(3), e5-e5.

Xu, H., Wen, L. M., Hardy, L. L., \& Rissel, C. (2016). Associations of outdoor play and screen time with nocturnal sleep duration and pattern among young children. Acta Paediatrica, 105(3), 297-303.

\section{Copyrights}

Copyright for this article is retained by the author(s), with first publication rights granted to the journal.

This is an open-access article distributed under the terms and conditions of the Creative Commons Attribution license (http://creativecommons.org/licenses/by/4.0/). 